\title{
Resistance of a new type of flat shear connectors dedicated to composite columns
}

\author{
M.P. Chrzanowski \\ Arcelor Mittal Steligence ${ }^{\circledR}$, Warsaw, Poland \\ C. Odenbreit \\ AMCSC, FSTM, RUES, University of Luxembourg, Luxembourg \\ R. Obiala \& T. Bogdan \\ Global R\&D, ArcelorMittal, Esch-sur-Alzette, Luxembourg \\ H. Degée \\ FET, CERG, Hasselt University, Hasselt, Belgium
}

\begin{abstract}
The current practice to assure composite action foresees the usage of headed studs. This type of mechanical shear connectors was developed for composite beams and only adopted for the column's usage. Application in composite columns could lead to a reduced economy, especially for heavy composite columns used in high-rise buildings. A new type of flat shear connectors was developed and characterized that allows for fully automatic application process. This secures an increased safety of the whole structure, improved performance, optimized cross-section, reduced manufacturing time and costs. The presented paper gives a short description about the development process and focuses on the proposed analytical model describing the resistance of flat shear connectors. The developed analytical model comprises the complex stress state, which is present in the highly confined concrete directly under the connectors. The assumptions and theoretical models were confirmed in complex nonlinear FE simulations performed in the Abaqus software.
\end{abstract}

\section{INTRODUCTION AND MOTIVATION}

Heavy composite columns with multiple encased steel profiles can be found in the structural systems of high-rise buildings, like for example IFC Tower 2 in Hong Kong. A clear trend that cities are build more vertical can be observed in the work of Al-Kodmany (2012). Modern high-rise buildings moved beyond the scopes of applicability of current design codes, like EN1994-1-1 (2004). Typical structural solutions became no more attractive. In the case of composite columns, normally shear connection at the steel-concrete interface is secured by the application of shear studs. There exist other types of connectors, like for example welded stiffeners SmartCoCo (2016), bar connectors Roik (1984), channel sections Johnson (2004), T-sections Roik (1980), burls Roik (1984), perfobond solution Vianna (2009) or bearing plates Roik (1988) \& Hanswille (2004). In some cases, this solutions bring a problematic application process, where the construction safety, economy and erection are hardly meet. An example of shear studs and their application is shown in Figure 1. A replacement of the commonly used shear connectors with a new and more efficient solution dedicated to columns would be highly beneficial. 
a)

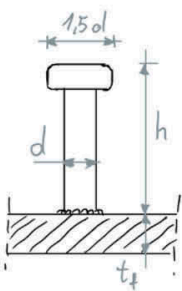

b)

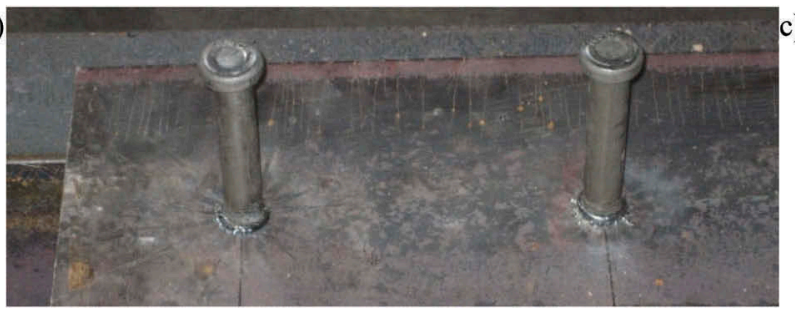

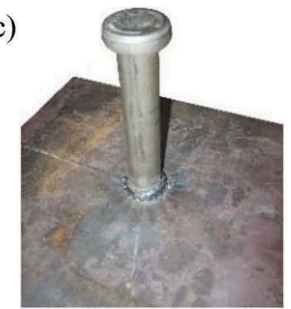

Figure 1. Shear studs: a) scheme, b) welding and c) detail (Source: DISCCO (2016)).

a)

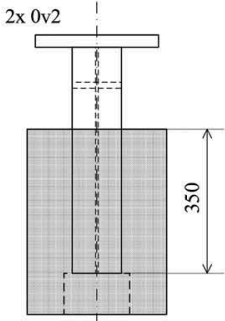

b)

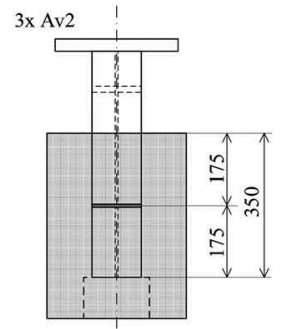

c)

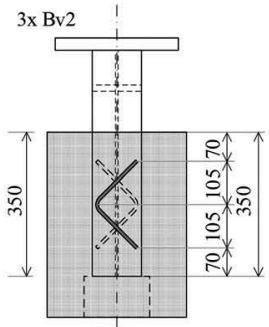

d)

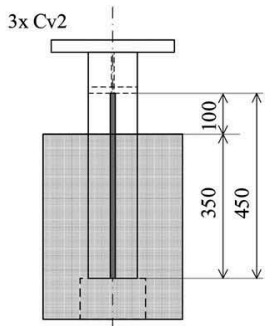

Figure 2. Layout of flat shear connectors: a) reference, b) transversal, c) V-shaped and d) longitudinal.

The developed new flat shear connectors dedicated to composite columns are made from regular reinforcement bars welded to the flanges of embedded steel profiles in a specific arrangement, as shown in Figure 2. Analysis of all variants, including distinction on mechanical bearing and bond phenomena, gave full understanding of the behaviour of flat shear connectors. Moreover, each variant can be subjected to the fully automatized application process. This directly improves the economy of the composite solution and help the entire construction process.

\section{TEST CAMPAIGN ON NOVEL SHEAR CONNECTORS}

To characterise the developed novel flat shear connectors, 11 column push-out tests were performed, where three variants of connectors - transversal, longitudinal and angled were tested, see Table 1. Two reference tests without mechanical shear connectors were included. All specimens had nominally identical geometry as shown in Figure 3. Detailed information about the test campaign can be found in Chrzanowski (2019).

The performed tests revealed the load-slip behaviour of flat shear connectors (Figure 4), where not only the load capacity was of importance, but also the stiffness and ductility. Failure patterns of tested connectors were studied in detail after opening of the specimens. Based on the taken observations and measurements, it can be observed that the best performance is indicated by the connector type Bv2, where all force transferring phenomena are combined. The occurred failure planes were noticed and respective strut-and-tie models were built. In order to investigate the load flux and precisely identify the failure sequence, numerical simulations in the 3D Finite Element (FE) software were crucial and supported the test campaign. The entire procedure, as well as the developed theoretical and numerical models are described in Chrzanowski (2019). 
a)

Reinforcement bars RB500B

(1) - longitudinal ø10

(2) - stirrups $\oslash 12$

(3) - U-links Ø12

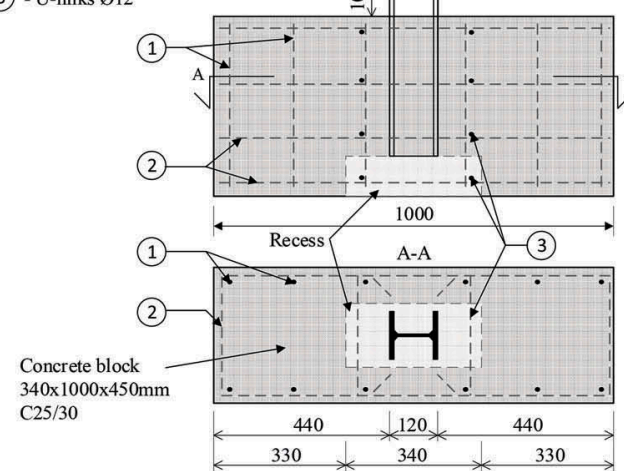

b)

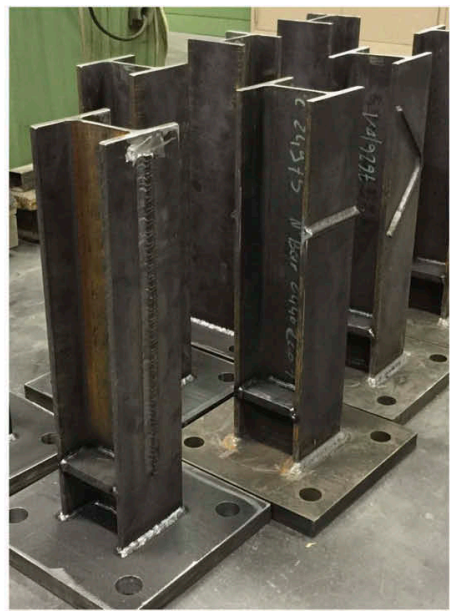

Figure 3. Geometry of push-out test specimens: a) scheme and b) view on welded flat shear connectors.

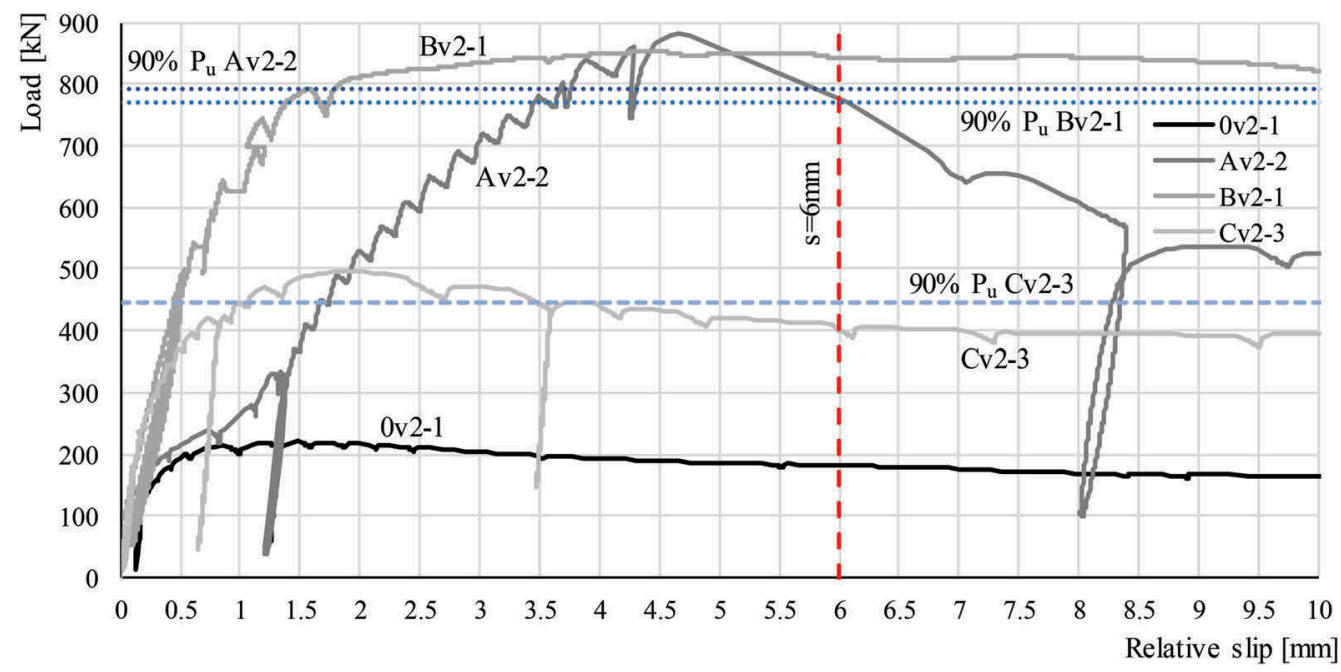

Figure 4. Load-slip behaviour of representative specimens for each type of flat shear connectors.

Table 1. Overview of the push-out test specimens.

\section{No of}

Series specimens Shear connection

0v2 2

Av2 3

Bv2 3

Cv2 3

\section{Reference tests: no connectors (Figure 2a)}

Flat shear connector, transversal

(Figure 2b)

Flat shear connector, angled, V-shaped

(Figure 2c)

Flat shear connector, longitudinal (Figure

2d)
Surface treatment

Cleaning: No

Coating: Release agent - demoulding oil 


\section{NUMERICAL SIMULATIONS OF THE PERFORMED PUSH-OUT TESTS}

Numerical simulations were performed in the FE code Abaqus (2017). Created models reflected the experimental campaign. In the developed models (i) the concrete confinement according to fib ModelCode 2010 (2000), (ii) the steel profile-concrete bond and (iii) connector-concrete bond were represented. All details about modelling are described in Chrzanowski (2019). Performed numerical study consisted of 267 simulations. A good coherence between the test and numerical results was obtained, as it can be observed in Figure 5.

\section{ANALYTICAL MODEL FOR THE RESISTANCE OF FLAT SHEAR CONNECTORS}

Based on the obtained load-slip curves (Figure 4), developed failure and strut-and-time models and insight to the load flux and failure sequences from FE simulations (Figure 5), the development of an analytical model describing the resistance of discussed novel flat connectors was possible. It is strictly referring to the test campaign and the following fundamental assumptions were used: (i) materials are homogenous, (ii) theory of elasticity covers the behaviour, (iii) stirrups are not undergoing deformation, (iv) long-term effects were disregarded and (v) no safety concept was used. The detailed derivation process can be found in Chrzanowski (2019).

The contribution of steel-concrete bond was assessed based on the reference specimens by employing an equation for the definition of stresses and removing the Coulomb frictional forces.

From the specimens with the longitudinal connector, the connector-concrete bond strength can be assessed. Considering only the contribution of the connector, all other contributing resistances should be removed, see Equation 1. Combining the relation for the definition of stresses and model from the fib ModelCode 2010 (2000) for the reinforcement bar-concrete anchorage strength $\tau_{b \max }=2.5 \sqrt{f_{c m}}$, where $f_{c m}$ is the mean concrete compression strength, the resistance of longitudinally oriented flat shear connector can be described by Equation 2.

$$
\begin{gathered}
F_{\text {connector }}=\left(F_{\text {test }}-F_{\text {bond steel prof }}-F_{\text {friction }}\right) / 2 \\
P_{R, b, C v 2}=2.5 \cdot \pi \cdot \lambda_{u} \cdot d \cdot L_{\text {emb }} \cdot \sqrt{f_{c m}}
\end{gathered}
$$

where $2=$ number of applied connectors, $\lambda_{u}=$ connector perimeter utilization factor, $d=$ connector diameter, $L_{e m b}=$ embedded length of the connector.

The transversal and longitudinal variants of flat shear connectors are specific cases of the angled variant, when the connector arm inclination angle is set to $90^{\circ}$ and $0^{\circ}$ respectively. In the angled variant, the vertical shearing of concrete should be considered in addition, as

a)

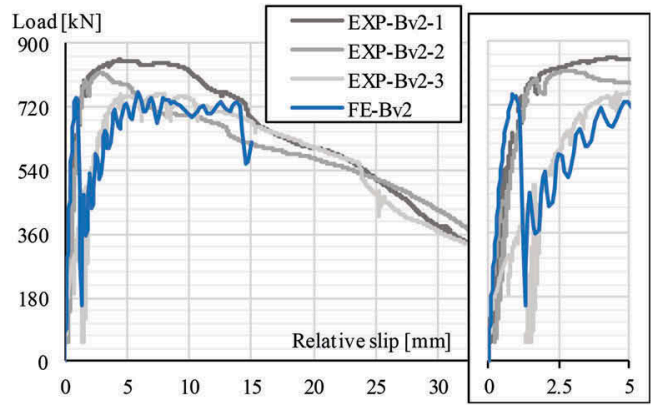

b)

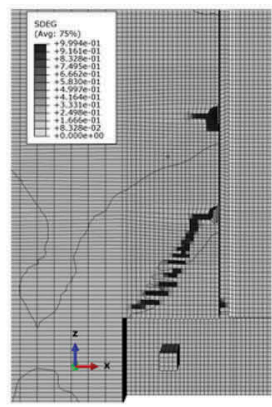

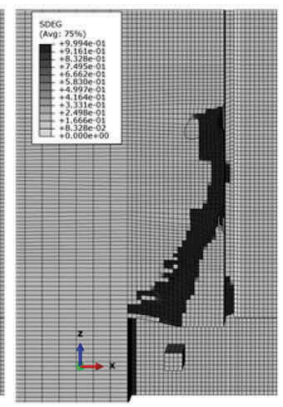

Figure 5. Results from the simulation of push-out specimen Bv2: a) load-slip and b) concrete damage. 
shown in Figure 6. The connector-concrete bond strength denoted as $P_{R, b}$, can be calculated according to Equation 2. The reaction forces can be split on each arm and projected into the pair of forces acting perpendicularly (Eq. 3) and tangentially (Eq. 4) on the connector surfaces.

$$
\begin{aligned}
& F_{n}=\frac{F_{R}}{n_{a}} \cdot \sqrt{\sin ^{2} \alpha_{c} \cdot \tan ^{2} \theta+\left(\sin \alpha_{c}+\cos \alpha_{c}\right)^{2}} \cdot \sin \beta \\
& F_{t}=\frac{F_{R}}{n_{a}} \cdot \sqrt{\sin ^{2} \alpha_{c} \cdot \tan ^{2} \theta+\left(\sin \alpha_{c}+\cos \alpha_{c}\right)^{2}} \cdot \cos \beta
\end{aligned}
$$

where $F_{R}=$ force acting on one connector, $n_{a}=$ number of connector arms, $\alpha_{c}=$ connector arm inclination angle, $\theta=$ angle of the concrete compression strut and $\beta=$ angle between the connector contact surface and the resultant acting force.

To evaluate resultant stresses in concrete, differential equations were needed to be solved and an assumption of full confinement was implemented. It was taken that in plane strain state, stresses in one direction are equal to stresses in another direction multiplied by the Poisson's ratio. The material law of concrete was based on the modified Mohr-Coulomb material law proposed by Nielsen \& Hoang (2011). Finally, the resistance of flat connectors, related to the concrete strength, can be described by three conditions: (i) maximum compression (Eqs. 5-6), (ii) maximum shear (Eqs. 7-8) and (iii) between-arm shearing (Eqs. 9-10). In addition, in Equation 11, a condition was given that checks if in principal direction tensile stresses can occur. When this condition is met, the confinement effect is vanished, and factors are set to $\omega_{c c}=1$ and $k_{s}=0$.

$$
\begin{gathered}
\sigma_{p 1}<f_{c m, c, c u b e} \\
P_{R, c}+P_{R, b}=\frac{n_{a} \cdot \lambda_{d} \cdot d \cdot L_{a r m} \cdot \omega_{c c} \cdot f_{c m, c u b e}}{\left(k_{s}+1\right) \cdot \psi_{B}-0.5 \cdot\left(k_{s}-1\right) \cdot \kappa_{1} \cdot(1+\nu)}+P_{R, b} \\
\tau_{\max }<\sigma_{s} \cdot \tan \varphi+c \\
P_{R, s 1}+P_{R, b}=\frac{n_{a} \cdot \lambda_{p} \cdot \nu_{s} \cdot d \cdot L_{a r m} \cdot f_{c m, c u b e}}{2 \sqrt{k_{s}} \cdot\left(\psi_{B}-0.5 \cdot \kappa_{1} \cdot(1+\nu) \cdot \mu\right) \cdot \sin \left(\alpha_{s 1}\right)}+P_{R, b} \\
\tau_{x 1 y 1}<\sigma_{x 1} \cdot \tan \varphi+c \\
P_{R, s 2}+P_{R, b}=\frac{n_{a} \cdot \lambda_{A} \cdot \nu_{s} \cdot \sin 2 \alpha_{c} \cdot L_{a r m}{ }^{2} \cdot f_{c m, c u b e}}{4 \sqrt{k_{s}} \cdot\left(\psi_{B, s 2,1}-\psi_{B, s 2,2} \cdot \mu\right)}+P_{R, b}
\end{gathered}
$$
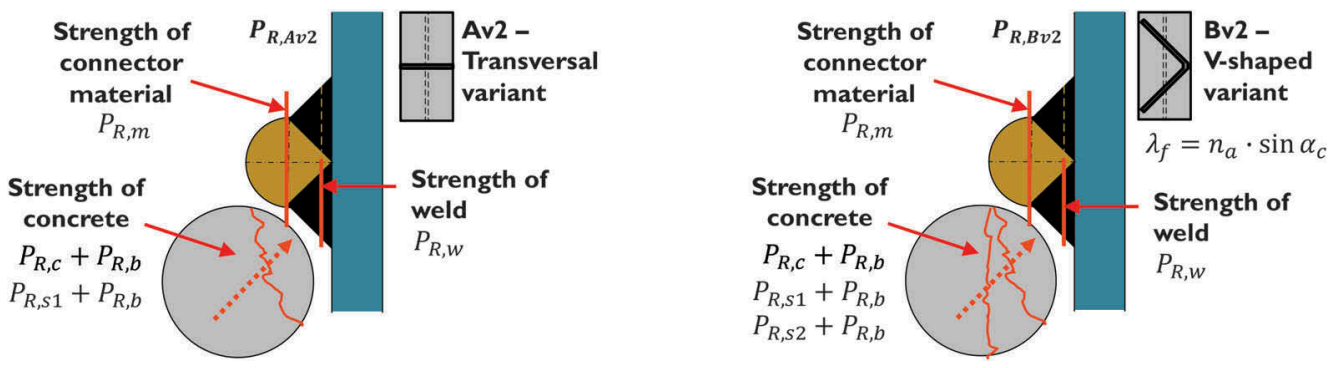

Figure 6. Failure modes of flat shear connectors, where $\lambda_{f}=$ force orientation factor, $P_{R, c}=$ resistance due to the maximum compression strength of concrete, $P_{R, s 1}=$ resistance due to the maximum shear strength of concrete, $P_{R, s 2}=$ resistance due to the between-arm shear strength of concrete, $P_{R, w}=$ resistance of weld and $P_{R, m}=$ resistance of connector material. 


$$
\frac{\kappa_{1} \cdot(1+\nu)}{2 \cdot \psi_{B}}<1
$$

where all used parameters are explained in Chrzanowski (2019), $f_{c m, c, c u b e}=$ confined strength of concrete, $\lambda_{d}=$ effective contact area factor, $L_{\text {arm }}=$ length of the arm of connector, $\omega_{c c}=$ transformation factor between confined Coulomb's material to the unconfined concrete strength, $f_{c m, c u b e}=$ mean compression strength of concrete, $k_{s}=$ inclination parameter for the Coulomb material, $\psi_{B}=$ simplification factor, $\kappa_{1}=$ load transformation factor, $\nu=$ Poisson's ratio of concrete, $\sigma_{s}=$ stress state in the normal direction corresponding to the maximum shear stress state, $\varphi=$ internal friction angle of concrete, $c=$ cohesion of concrete material, $\lambda_{p}=$ projection factor, $\nu_{s}=$ concrete cohesion reduction factor due to microcracking, $\mu=\tan -$ gent of internal friction angle of concrete, $\alpha_{s 1}=$ angle between the resulting shear plane and direction of flange of steel profile, $\tau_{x 1 y 1}=$ shear stresses in the between-arm shearing direction, $\sigma_{x 1}=$ normal stresses corresponding to the between-arm shearing stress state, $\lambda_{A}=$ shearing area correction factor, $\psi_{B, s 2,1}$ and $\psi_{B, s 2,2}=$ simplification factors.

The strengths of steel parts complete the resistance model. The weld resistance was evaluated based on the directional method of EN 1993-1-8 (2005), see Equation 12. The resistance of connector material is related to the plastic shear resistance and is given in Equation 14.

$$
\begin{gathered}
P_{R, w}=\frac{\lambda_{f} \cdot f_{u}}{\beta_{w} \cdot \psi_{w, e l / p l}} \\
\psi_{w, e l}=\sqrt{\frac{e_{w}{ }^{2} \cdot z^{2}}{I_{w}{ }^{2}}+3 \cdot \frac{1}{A_{w}{ }^{2}}} \psi_{w, p l}=\sqrt{\frac{e_{w}{ }^{2}}{d^{2} \cdot A_{w, t}{ }^{2}}+3 \cdot \frac{1}{A_{w}{ }^{2}}} \\
P_{R, m}=\frac{\lambda_{f} \cdot d \cdot L_{c o n} \cdot f_{y}}{\sqrt{3}}
\end{gathered}
$$

where $f_{u}=$ tensile strength of welded material, $\beta_{w}=$ weld parameter from EN1993-1-8, $e_{w}=$ force eccentricity acting on welded connection, $z=$ distance between weld centre of gravity and most external fibre in tension, $I_{w}=$ moment of inertia of welded connection, $A_{w}=$ area of welded connection, $A_{w, t}=$ area of weld subjected to tension, $f_{y}=$ yielding strength of connector. Areas of welds are according to the vertical weld centroid plane indicated in Figure 6.

\section{SUMMARY AND CONCLUSIONS}

In the presented paper, a comprehensive summary on the characterisation process of the developed flat shear connectors dedicated to composite columns and following innovative analytical model describing their resistance was given. Based on the conducted research, it can be observed that the angled, V-shaped variant of flat shear connector shows the best performance from the tested flat connectors. Moreover, the developed analytical model for this variant of connector creates one coherent model, which comprises all force transferring phenomena and failure modes of tested connectors. All details can be found in Chrzanowski (2019).

The presented analytical model was derived to strictly describe the load bearing resistance of the tested shear connectors and also to reflect the observed and possible failure modes. To increase the accuracy with test results, calibration factors were needed to artificially increase the strength of concrete - the compression strength (Equation 5) and shear strength (Equation 9) in the confined concrete state. Unfactored ratio of analytically calculated resistance to the experimentally obtained resistance for $\mathrm{V}$-shaped variant of connector varied from 0.65 for concrete crushing to 0.84 for concrete shearing. An exact match with the test results was achieved after putting 
in front of the resistance part in Equations $5 \& 9$ a factor 2.2 and 1.3 for the concrete compression and shear strengths, respectively. A conclusion can be drafted is that the currently available concrete confinement models, Nielsen (2011) \& fib ModelCode2010 (2000), are not precisely dealing with the heavy local 3D confinement of the concrete, which occurred in the zone beneath the flat shear connectors. The developed model consists of limitations due to the scope of performed test campaign and taken assumptions. Further studies are needed to investigate the calibration aspect and to extrapolate the proposed model.

\section{REFERENCES}

Al-Kodmany, K.: The Logic of Vertical Density: Tall Buildings in the 21st Century City, International Journal of High-Rise Buildings, CTBUH Korea, Vol. 1, No. 2, 131-148, 2012.

Chrzanowski, M.: Shear Transfer in Heavy Steel-Concrete Composite Columns with Multiple Encased Steel Profiles, PhD Thesis, University of Luxembourg, 2019. DOI: http://hdl.handle.net/10993/40011.

DISCCO, Development of improved shear connection rules in composite beams, European Commission, Research Programme of the Research Funds for Coal and Steel, TGS 8, RFSR-CT-2012-00030, 2016.

EN 1993-1-8, Eurocode 3: Design of steel structures - Part 1-8: Design of joints, European Standard, European Committee for Standardization, Brussels, 05. 2005.

EN 1994-1-1, Eurocode 4: Design of composite steel and concrete structures - Part 1-1: General rules and rules for buildings, European Standard, European Committee for Standardization, Brussels, 12.2004

fib Model Code for Concrete Structures 2010, Special Activity Group 5, International Federation for Structural Concrete (fib), Ernst\&Sohn, 2000. ISBN 978-3-433-03061-5.

Hanswille, G.; Porsch, M.: Lasteinleitung bei ausbetonierten Hohlprofil-Verbundstützen, Stahlbau, Ernst\&Sohn, Vol. 73, No. 9, 2004.

Houston, W.; Houston, I.: How to properly specify weld studs for use with the drawn arc stud welding process in structural applications, Modern Steel Construction, Solid Bond, steelwise, June 2015.

Johnson, R.P.: Composite Structures of Steel and Concrete. Beams, Slabs, Columns and Frames for Buildings, Third Edition, Blackwell Publishing, 2004. ISBN 1-4051-0035-4.

Nielsen, M.P.; Hoang, L.C.: Limit Analysis and Concrete Plasticity, Third Edition, CRC Press, Taylor \& Francis Group, 2011. ISBN 978-1-4398-0396-7.

Roik, K.; Bode, H.; Breit, M.: Momentfreie Anschlüsse an einbetonierte Stahlprofilstützen, Projekt 53, Studiengesellschaft für Anwendungstechnik von Eisen und Stahl e.V., 1980.

Roik, K.; Breit, M.; Schwalbenhofer, K.: Untersuchung der Verbundwirkung zwischen Stahlprofil und Beton bei Stützenkonstruktionen, Projekt 51, Studiengesellschaft für Anwendungstechnik von Eisen und Stahl e.V., 1984.

Roik, K.; Schwalbenhofer, K: Experimentelle Untersuchungen zum plastischen Verhalten von Verbundstützen, Projekt 125, Studiengesellschaft für Anwendungstechnik von Eisen und Stahl e.V., 1988.

SIMULIA User Assistance 2017, Abaqus, Dassault Systèmes Simulia Corp., Providence, RI, USA.

SmartCoCo, Smart Composite Components - Concrete Structures Reinforced by Steel Profiles, Technical Report, European Commission, Research Programme of the Research Funds for Coal and Steel, TGS8, RFSR-CT-2012-00031, 2016.

Vianna, J. da C.; Costa-Neves, L.F.; Vellasco, P.C.G. da S.; de Andrade, S.A.L.: Experimental assessment of Perfobond and T-Perfobond shear connector' structural response, Journal of Constructional Steel Research, Elsevier, 65, 408-421, 2009. 